\title{
Editorial
}

\section{The Journal of Perinatology: Revisited}

\section{Gilbert I. Martin, MD}

"It takes a great deal of history to produce a little literature."

Henry James（Hawthorne, 1879)

This will be my last editorial as editor-in-chief of the Journal of Perinatology. The history of the Journal is brief (20 years) and although the amount of literature produced can be considered small, I believe that the editorial content has influenced the way we care for our patients. The Journal originally named the Journal of the California Perinatal Association has grown from two issues in 1981 to eight issues plus supplements in 2000. Along this pathway we have worked with several publishing groups, and Laura Kosden at Appleton-Century, Susan Patterson at Mosby-Yearbook, and Chris Rawlins at Nature Publications should be mentioned for their dedication to excellence in the peer-review process. The editorial board and panel of referees have also expanded and all have played an integral part in the establishment of the Journal as a respected national and international publication. There are two individuals who deserve recognition for their dedication to the Journal from its inception. Rita Reiff, the editorial assistant, directing the editorial office, is a name familiar to authors throughout the world for her polite, caring nature and for her knowledge of where each article was in the editorial process. Jeffrey Pomerance who in 1981 was one of the cofounders of the Journal has remained the conscience of the peer-review process. Objective, honest and dedicated he has set the highest standard for all involved in editorial review. In the early days he painfully rewrote and reedited many of the submissions. Today, his familiar notations on manuscripts have been of great benefit to all.

Yes, it is time for a change. . .a next step as we enter a new millennium. The Journal, now the official publication of the Perinatal Section of the American Academy of Pediatrics is widening its horizons as we expand internationally. We are fortunate to have Dr. Edward E. "Ned" Lawson who will assume the duties of editorin-chief. Ned is the Chief of the Division of Neonatology at John Hopkins School of Medicine and has great clinical, investigative and editorial experience. With his "eye to the future," the Journal will offer many innovative ideas in future years.

This has been a wonderful 20 years for me personally. I have learned a great deal, have made lasting relationships and have been able to keep "up with the current literature," for I was an insider to the entire process. I am extremely proud of the accomplishments of the Journal of Perinatology and believe that our peer-review process was successful in assisting authors in improving their manuscripts and thus improving the quality of health care.

The editor-in-chief of any Journal faces many challenges. It is fitting that I leave you with a poem entitled: The Editor's Dilemma 


\section{THE EDITOR'S DILEMMA}

I've been a journal editor, for twenty years or more.

I've scanned, critiqued and referred out, articles by the score.

The manuscript that you send in, prepared in triplicate.

Needs to follow certain steps, or else it will not fit.

State the title, name the authors, choose one to correspond.

Be specific to a section, or else it will not bond.

A simple letter, a brand new concept, may be the way to start.

Or conjure up an editorial, emanating from your heart.

Words should flow with clarity, syntax with a style.

Don't obfuscate, abbreviate, you will find yourself febrile.

Tautology, the passive voice, jargon which disturbs.

Simplicity without excess, use the proper verbs.

Statistics, such a fearsome thought, student's test, chi square.

Kruskall-Wallace, selection bias, these terms just are unfair.

If your work is randomized, double blind and dull.

Remember the hypothesis, must satisfy the null.

In the perinatal world, the language is specific.

If we had our own vocabulary, wouldn't that be terrific?

Ebonics is a brand new term

Which deals with history.

Perhaps we need our own creation, and then we will be free.

I've thought a bit, produced a term, without those histrionics.

The language mode that I have coined.

Is known as "perinonics"

GBS and PDA, words abbreviated, will now become single nouns,

And can be simple stated.

The editors will soon applaud, we'll think of you as sages.

The end result will surely be, a piece with fewer pages.

Sit down, create, a manuscript, submit it without tremor.

Sit back and wait, and wait, and wait, the editor's dilemma. 